\title{
A apropriação do cerrada baiano pelo agronegócio: novos usos do território e as mudanças socioeconômicas e socioespaciais
}

\section{The appropriation from the cerrado baiano to agribusiness: new uses of the territory and the socio-economic and socio-spatial changes}

Rita de cássia evangelista dos santos *

\section{Resumo:}

O artigo analisa o processo de apropriação do Cerrado baiano pelo agronegócio e as mudanças no uso do território bem como as mudanças socioeconômicas e socioespaciais decorrentes desses novos usos. O Oeste da Bahia vem passando por um processo de modernização da agricultura desde o final da década de 1970 empreendido por sujeitos capitalizados provenientes do sul e sudeste do país, por empresas e pelo Estado, impondo novos usos ao território, que passa a obedecer ordens externas. Desse processo, decorre um fluxo migratório em direção à região Oeste da Bahia e grandes mudanças socioespaciais.
* Professora do Instituto Federal de Educação Ciência e Tecnologia da Bahia - campus Barreiras. Mestranda do PPGeo IESA - UFG
Abstract:

The article analyzes the appropriation process of the Cerrado Baiano by agribusiness and changes at using the territory as well as socio-economic and socio-spatial changes resulting from these new uses.The West from Bahia is going through an agricultural modernization process since the late 1970 s undertaken by capitalized subject from the south and southeast of the country by companies and the state, imposing new uses of the territory, which shall comply with external orders. In this process, there is a migration toward the West region of Bahia and so many socio-spatial changes.
Palavras-chave:

Cerrado baiano, agronegócio, território

Key-Words:

Cerrado baiano, agribusiness, territory 


\section{CONSIDERAÇÕES INICIAIS}

A implementação da agricultura modernizada no Cerrado brasileiro pode ser compreendida como uma estratégia do capital, na sua fase atual, globalizada, no sentido de ampliar suas bases produtivas em seu processo de acumulação. Dessa forma, o Cerrado que era visto, de forma estereotipa$\mathrm{da}$, como um local de natureza pobre, passa a ser alvo de pesquisas, melhoramento dos solos, e local privilegiado para uma agricultura com base na técnica, ciência e informação, tendo como atores principais os agricultores sulistas capitalizados (ou subsidiados pelo Estado através de empréstimos), as empresas (principalmente as transnacionais) e o Estado como ordenador de políticas territoriais, comandado pelas relações capitalistas de produção.

Para Calaça $(2011$, p. 2) o Estado cria as condições propícias para a incorporação do Cerrado à divisão territorial do trabalho através da pesquisa (EMBRAPA) e do financiamento, utilizando os bancos públicos, tornando atraente, "aos atores hegemônicos a incorporação do Cerrado ao processo produtivo, comandado pelos interesses do mercado, com rentabilidade e lucratividade".

A apropriação do Cerrado pelo agronegó-

cio que se inicia na região Centro - Oeste na década de 1970 expande-se também para o Cerrado baiano, principalmente a partir da década de 1980, impondo novos usos ao território pelos atores hegemônicos do capital, incluindo o Oeste da Bahia no circuito superior da economia.

Nesse sentido, o artigo tem como objetivos: analisar o processo de apropriação do Cerrado baiano pelo agronegócio buscando compreender os novos usos impostos ao território; e, compreender as mudanças socioeconômicas e socioespaciais da microrregião de Barreiras a partir da implementação do agronegócio nessa porção do espaço baiano.

A metodologia consistiu em revisão bibliográ-

fica e análise de alguns dados socioeconômicos dos municípios da microrregião de Barreiras presentes no Atlas de Desenvolvimento Humano - 2013, dados estes baseados nos censos demográficos de 1991, 2000 e 2010.

\section{A APROPRIAÇÃO DO CERRADO BAIANO PELO}

\section{AGRONEGÓCIO: OS NOVOS USOS DO TERRITÓ-} $\mathrm{RIO}$

A região Oeste da Bahia vem experimentando desde o final da década de 1970 um grande surto de crescimento econômico fruto da dinâmica dos novos arranjos territoriais do Capitalismo global. $\mathrm{Na}$ fase atual do Capitalismo, a produção é flexível e se molda às demandas dos mercados a nível global e o território é chamado a reorganizar-se também na tentativa de atender a essas demandas.

Para Milton Santos $(2006$, p. 88 ) a agricultura representou, desde os primórdios, uma atividade reveladora da forte ligação entre as sociedades e seu entorno, ou seja, as relações eram estabelecidas entre os grupos humanos e a natureza. Porém, com a criação e a difusão das técnicas houve maior capacidade de modificação da natureza, reduzindo cada vez mais seus impactos e modificando a importância dos seus resultados. Assim,

Os últimos séculos marcam, para a vida agrícola, com a humanização e a mecanização do espaço geográfico, uma considerável mudança de qualidade, chegando-se, recentemente, à constituição de um meio geográfico a que podemos chamar de meio técnico-científico-informacional, característico não apenas da vida urbana mas também do mundo rural, tanto nos países avançados como nas regiões mais desenvolvidas dos países pobres. É desse modo que se instala uma agricultura propriamente científica, responsável por mudanças profundas quanto à produção agrícola e quanto à vida de relações (SANTOS, 2006, p. 88).

Ainda segundo Santos (2006), no atual momento da história da humanidade, podemos falar de uma agricultura científica globalizada, pois quando a produção agrícola tem referência planetária ela recebe influência das mesmas leis que regem outros aspectos da produção econômica. Essa agricultura é exigente de ciência, tecnologia e informação, levando a um grande aumento da produtividade com relação à área plantada e o dinheiro passa a ser uma "informação" indispensável. Logo,

Nas áreas onde essa agricultura científica globalizada se instala, verifica-se uma importante demanda de bens científicos (sementes, inseticidas, fertilizantes, corretivos) e, também, de assistência técnica. Os produtos são escoIhidos segundo uma base mercantil, o que também implica uma estrita obediência aos mandamentos científicos e técnicos. São essas condições que regem os processos de plantação, colheita, armazenamento, empacotamen- 
to, transportes e comercialização, levando à introdução, aprofundamento e difusão de processos de racionalização que se contagiam mutuamente, propondo a instalação de sistemismos, que atravessam o território e a sociedade, levando, com a racionalização das práticas, a uma certa homogeneização (SANTOS, 2006, p. 89).

Nesse sentido, no Brasil, a partir da década de 1960, os setores produtivos vêm passando por grande reestruturação produtiva no intuito de atender aos reclames externos. No tocante à agropecuária, esta, vem sofrendo grandes transformações, reestruturando os espaços rurais e urbanos, dotando-os de novos sistemas de objetos e sistemas de ações (SANTOS, 2004), baseado nos componentes de ciência, tecnologia e informação.

As transformações ocorridas no campo brasileiro após a década de 1960 são caracterizadas pela incorporação do progresso técnico, cuja principal função é criar condicionantes para uma maior produtividade da terra e do trabalho e também submeter o processo produtivo ao capital, cada vez mais internacionalizado através da ação de grandes corporações transnacionais que tem investido nas atividades agropecuárias no Brasil. Essa modernização da agricultura requer um aumento de capitais fixos para investimentos em terras e maquinários e capitais móveis para investir nas exigências técnicas e científicas (MATOS; PESSÔA, 2014, p. 8). Dessa modernização tecnológica da agricultura, surgem as empresas capitalistas rurais e dessa forma, os empresários rurais. Para Mendonça (2004) o empresário rural "surge", pois não houve a transformação do camponês em empresário, mas a substituição; muitas vezes pelo homem citadino.

Para Santos (2006) há também, de certa forma, um militarização do trabalho, pois o critério de sucesso é a obediência às regras sugeridas pelas atividades hegemônicas, e aqueles agentes que se recusam a obedecer tais regras acabam por ser deslocados. Nesse sentido, "é atender a tais imperativos ou sair" (SANTOS, 2006, p. 89).

Mas as transformações técnico-científicas que vêm ocorrendo no campo nas áreas de Cerrado não dizem respeito apenas ao processo produtivo, pois,

A consolidação da agricultura moderna causou graves danos sociais e ambientais, evidentes, como a concentração de terra e renda, a precarização do trabalho, deslo- camento da força produtiva do campo para as cidades e, também, destruição e contaminação do meio ambiente. Ou seja, a modernização foi uma falsa imagem de progresso, um mito, produto do discurso de desenvolvimento rural (MATOS; PESSÔA, 2014, p. 8).

No tocante à apropriação de áreas do Cerrado brasileiro após a década de 1970, ela se concentra inicialmente nos estados da região Centro-Oeste e há um grande esforço do Estado e agentes privados no sentido da modernização do território, implementando uma agropecuária com base na ciência, tecnologia e informação, seguindo a tendência do Sul e Sudeste do país. Isso significou a abertura de uma nova fronteira agrícola tendo as áreas de Cerrado como prioritárias devido a alguns fatores: relevo plano em grande parte do Cerrado, terras fartas e com baixos preços, grande disponibilidade hídrica. Esses fatores em conjunto, concorreram para a implementação de uma agricultura moderna, capaz de atender às demandas a nível nacional e internacional, tendo como os principais sujeitos os sulistas, que de certa forma, já dispunham de conhecimentos técnicos adquiridos em suas regiões de origem.

Para Matos e Pessôa (2014), em se tratando da apropriação do Cerrado pelo agronegócio, o Estado teve participação ativa por meio de incentivos fiscais, crédito agrícola, subsídios à exportação e investimentos em infraestrutura como eletrificação rural, sistemas de armazenamento e beneficiamento, construção e pavimentação de estradas, ferrovias, construção e ampliação de portos.

O Estado, a partir de políticas planejadas, direciona a expansão do capital, ao mesmo tempo promove a ocupação e a interligação da porção central do país com a transferência da capital e com a implementação da ação modernizadora da agricultura. A partir da década de 1970, com o II PND (Plano Nacional de Desenvolvimento) essas ações se tornam mais fortes. As políticas de desenvolvimento contidas no II PND conjuntamente com as características físicas do Cerrado: topografia, recursos hídricos, clima, propiciam a efetiva ocupação das terras para a produção da monocultura de grãos. Além disso, a posição geográfica do Centro-Oeste e a construção de estradas ligando-o a outras áreas do país foram de grande importância, pois "os investimentos na logística constituíram medida indispensável para o adequado movimento da produção" (MATOS; PESSÔA, 2014 p. 11). 
Além disso,

Para propagar a agricultura moderna no Cerrado, alguns programas foram criados. Os de maior destaque, no âmbito da inserção de capital e tecnologia, foram o POLO CENTRO (Programa de Desenvolvimento dos Cerrados) e o PRODECER (Programa Nipo-Brasileiro de Desenvolvimento Agrícola da Região dos Cerrados). O primeiro foi criado em 1975 pelo Governo Federal. Visava à incorporação das áreas de Cerrado ao processo produtivo nacional e internacional por meio de subsídios. Para efetivar o programa, foram selecionadas áreas nos estados de Minas Gerais, Goiás, Mato Grosso do Sul e Mato Grosso. Todas as áreas escolhidas já possuíam alguma infraestrutura, estradas vicinais e eletrificação, proximidade com minas de calcário e potencial agrícola favorável, pré-requisitos básicos para suas escolhas. Com base nesses pré-requisitos, as áreas eram classificadas como "prioritárias" ou "secundárias." As áreas beneficiadas recebiam investimentos em fixos e fluxos (MATOS; PESSOA, p. 11).

A partir do final da década de 1970, o capital, em busca de novas áreas para a expansão do agronegócio, começa a metamorfosear também a região Oeste da Bahia, área de Cerrado com baixa produtividade econômica e baixa densidade populacional, abrindo assim, mais uma fronteira agrícola no estado.

Até a primeira metade do século $X X$, o Oeste da Bahia representava um imenso território de reserva, com um povoamento escasso e produção econômica baseada na agropecuária tradicional policultora e de subsistência e atividades extrativistas. Assim,

\begin{abstract}
Se nos dias atuais, o Oeste Baiano é considerado uma das mais im $\neg$ portantes regiões agroindustriais do Brasil, e o vigoroso crescimento recente da população urbana é revelador das grandes transformações socioespaciais ocorridas nos últimos trinta anos naquele vasto território à esquerda do Rio São Francisco, o mesmo não se pode afirmar quando este mesmo tratamento analítico se aplica ao seu passado (BRANDÃO, 2009, p. 54).
\end{abstract}

Nesse sentido, o uso do território no Oeste da Bahia até a primeira metade do século XX estava ligado ao que Milton Santos denominou de meio técnico, com uma produção agrária em moldes tradicionais e que abastecia basicamente o mercado estadual e, em menor escala os de outros estados.

A partir do final da década de 1970 e principalmente da década de 1980 , seguindo a conjuntura econômica nacional, o território do Oeste da Bahia é chamado a compor o quadro das novas ações do Estado e dos agentes privados (indivíduos e empresas) em seu projeto de modernização da agricultura para atender às demandas dos mercados nacional e inter- nacional.

Para Santos (1999), tudo que é considerado essencial atualmente se faz a partir do conhecimento do que é o território pois, "o Território é o lugar em que desembocam todas as ações, todas as paixões, todos os poderes, todas as forças, todas as fraquezas, isto é, onde a história do homem plenamente se realiza a partir das manifestações da sua existência" (SANTOS, 1999, p. 9).

Raffestin (1993, p. 144; 152) afirma que o território se forma a partir do espaço, sendo o resultado de uma ação conduzida por um ator sintagmático, ou seja, um ator que realiza um programa. É um espaço onde se projetou um trabalho e revela relações marcadas pelo poder. O território é uma produção a partir do espaço, se inscrevendo em um campo de poder, destacando as ações das empresas e das políticas espaciais dos Estados que agem sobre o território conforme seus interesses de controle, fazendo com que o espaço exista em função dos objetivos intencionais do ator, no entanto, não somente as empresas e os Estados, mas todos nós elaboramos estratégias de produção.

Para Goméz (2001, p. 20-21), o território é um conceito relacional que insinua um conjunto de vínculos de domínio, de poder, de pertencimento ou de apropriação entre uma porção ou a totalidade do espaço geográfico e um determinado sujeito individual ou coletivo. As dimensões políticas e afetivas são inevitáveis ao se tratar do território. Ele afirma que quando falamos em território sempre estamos assumindo, ainda que de maneira implícita, a existência de um espaço geográfico e de um sujeito que exerce sobre ele certo domínio, uma relação de poder, uma qualidade de possuidor. Para o autor, a relação de pertencimento ou apropriação não se refere somente a vínculos de propriedade, mas aqueles laços subjetivos de identidade e afeto existentes entre o sujeito e seu território. O território é, portanto, o espaço geográfico revestido das dimensões política, identitária e afetiva, ou de todas elas.

Notadamente, o controle do território bem como os seus usos, são dados a partir das territorialidades exercidas pelos sujeitos (individuais ou coletivos), ou seja, suas estratégias no que concerne ao arranjo espacial ou no seu uso. Assim, Goméz (2001, p. 22-23) entende por territorialidade, o grau de do- 
mínio que determinado sujeito individual ou coletivo possui em certo território ou espaço geográfico, assim como o conjunto de práticas e suas expressões materiais e simbólicas, capazes de garantir a apropriação e permanência de um território a um determinado agente individual ou social. Sendo assim, em um mesmo território podem haver vários sujeitos exercendo domínio territorial (territorialidades). As territorialidades podem ser exercidas por grupos sociais, grupos étnicos, empresas, Estados nacionais. As territorialidades criam-se, recriam-se e transformam-se historicamente em processos complexos de territorialização e desterritorialização, impulsionados através de mecanismos consensuais ou conflitivos de caráter gradual ou abrupto.

Com relação aos novos usos do território do Oeste da Bahia, estes, consubstanciam-se por diferentes sujeitos (indivíduos capitalizados, principalmente os sulistas, e empresas) sob a tutela do Estado, principalmente a partir da segunda metade da década de 1980 com o lançamento do PRODECER II que insere o Cerrado baiano no roteiro da modernização agrícola brasileira. A partir de então, novos sujeitos começam a exercer suas territorialidades no Cerrado baiano produzindo principalmente grãos (soja e miIho) e algodão, na forma de Commodities com uso intensivo de máquinas agrícolas e defensivos químicos, com a finalidade de aumentar a produção, atendendo assim aos mercados nacional e internacional, inserindo o Oeste da Bahia no circuito superior da economia. Esses sujeitos, notadamente os sulistas, sentem-se atraídos pela grande disponibilidade e baixo custo das terras para a agricultura e instalam-se principalmente em Barreiras e seu entorno, carregando consigo, em muitos casos, o domínio das técnicas modernas já instaladas no Sul e Sudeste do país.

Porém, os novos sujeitos que migram para o Cerrado baiano encontram ali, outros sujeitos, exercendo outras territorialidades e esse encontro, em muitos casos gerou conflitos por terras entre os que chegavam para implantar a agricultura mecanizada e os camponeses que já ocupavam o espaço com a agropecuária tradicional. Dessa forma, com a abertura de uma nova fronteira agrícola no Cerrado baiano, surge também uma nova estrutura fundiária que se mostra bastante conflituosa resultante da ação direta dos três agentes responsáveis pela modernização da agricultura: os agentes individuais capitalizados, as empresas e o Estado. Para Diniz (1982), esses três agentes produzem choques em qualquer espaço que penetram. Assim, "conflitos diretos são gerados quando 'gaúchos', 'paranaenses' e empresas cercam áreas imensas dos Gerais e criam atritos com posseiros e agregados" (DINIZ, 1982, p. 132). Para este autor, os conflitos vão além daqueles criados a partir da violência física (mortes, incêndios e destruição). Nesse sentido, "o conceito precisa ser ampliado para englobar as desapropriações injustas, a compra de pequenas propriedades e de benfeitorias por preços ínimos, que desestruturam o camponês e sujeitam-no ao assalariamento, à miséria, à fome e ao subemprego" (DINIZ, 1982, p. 133).

Para Calaça (2011), o território é resultado da ação de diversos atores que se territorializam em um processo histórico-espacial sempre em transformação. Para este autor,

A territorialização é articulada e dominada pelos interesses dos atores hegemônicos, que disputam com os atores já territorializados, e busca impor a sua lógica. Nesse sentido é importante para o processo de análise, da dinâmica territorial, identificar os atores territoriais envolvidos no jogo territorial, os conflitos que se estabelecem, as alianças que se efetivam, as subordinações que se concretizam (CALAÇA, 2011, p. 9).

Com a implementação e modernização da rede viária, o Oeste da Bahia ganha novo impulso principalmente a partir da década de 1980, e suas terras começam a ser valorizadas atraindo investidores. A soja, por exemplo, começa a ser produzida fortemente a partir desta década com base em financiamentos do governo federal com o intuito de ocupação e modernização das áreas de cerrado e para a divulgação dos resultados obtidos pelas pesquisas de melhoramentos agrícolas da EMBRAPA. Essa apropriação baseou-se no uso de tecnologias modernas, possibilitando assim o desenvolvimento agrícola em uma área tida como de solos pobres e pouco aproveitáveis para a agricultura, criando assim, modernos complexos agroindustriais e causando grandes transformações socioespaciais. Esses novos usos do território pelo agronegócio enfraquecem e desestruturam as antigas atividades econômicas da região ainda que, não as tenham exterminado, pois muitos pequenos produtores ainda permanecem no campo na tentativa de produzir principalmente gêneros alimentícios. Esses novos usos também acarretaram 
muitas mudanças socioeconômicas que precisam ser analisadas para que se tenha uma melhor compreensão do "papel dos agentes de produção do espaço e as transformações e permanências que se pode verificar no território a partir da atuação dessas forças, revelando as espacialidades próprias de cada momento da história que, neste caso, diz respeito ao Oeste Baiano" (BRANDÃO, 2010, p. 37).

\section{MUDANCAS DEMOGRÁFICAS E SOCIOECO- NÔMICAS D̉A MICRORREGIÃO DE BARREIRAS - BA COM A INCORPORAÇÃO DO AGRONEGÓCIO}

Os novos usos do território a que foi submetido o Oeste da Bahia a partir do final da década de 1970 e com maior intensidade a partir da década de 1980, acarretaram grandes mudanças econômicas e socioespaciais nessa porção do espaço baiano. Para este texto, analisaremos alguns indicadores socioeconômicos da microrregião de Barreiras - BA, microrregião essa onde se iniciou o processo de modernização da agricultura no Cerrado baiano. A microrregião em questão é composta por sete municípios: Baianópolis, Barreiras, Catolândia, Formosa do Rio Preto, Luís Eduardo Magalhães, Riachão das Neves, São Desidério. Os indicadores selecionados são: população total; índice de desenvolvimento humano (IDH); mortalidade infantil; índice de Gini; desigualdade de renda. Os dados foram extraídos do Atlas de Desenvolvimento Humano - 2013 e são baseados nos censos demográficos dos anos 1991, 2000 e 2010.

Com a implantação da agricultura moderna, o Oeste da Bahia, principalmente a microrregião de Barreiras, torna-se um espaço atrativo não somente para os sujeitos capitalizados e empresas interessados em investir na região, como para muitas pessoas em busca de emprego e melhores condições de vida. Dessa forma, essa porção do espaço baiano, tem recebido grande número de migrantes que se instalam principalmente nos municípios de Barreiras e Luís Eduardo Magalhães, fazendo com que esses municípios tenham grande crescimento populacional no período analisado conforme tabela 1.

A análise da tabela acima, nos permite perceber que houve um grande incremento populacional nos municípios que possuem maior relação com o agronegócio: Barreiras, Formosa do Rio Preto, Luís Eduardo Magalhães e São Desidério. Destes, destacam-se os municípios de Barreiras e Luís Eduardo
Magalhães que já são considerados como cidades do agronegócio, exercendo assim novas funcionalidades. Neste caso,

Barreiras se caracteriza como o centro financeiro, comercial e gestor do agronegócio e Luís Eduardo Magalhães como o centro da produção agrícola, sobretudo, para o mercado exterior. Contudo, esses dois municípios, se circunscrevem como pontos nodais de grande produção de soja, milho e de algodão, especialmente, sendo caracterizados por isso, como o lugar modelado por essa modernização do capital (global) que, pela sua rapidez e intensidade, transformou em pouco tempo as relações políticas e econômicas desses municípios e da região (MONDARDO, 2010, p. 274. Grifos do autor).

Tabela 1: População total dos municípios da microrregião de Barreiras - BA, 1991 a 2010.

\begin{tabular}{l|r|r|r}
\hline Localidades & $\begin{array}{l}\text { População total } \\
(1991)\end{array}$ & $\begin{array}{l}\text { População total } \\
(2000)\end{array}$ & $\begin{array}{l}\text { População total } \\
(2010)\end{array}$ \\
\hline Baianópolis (BA) & 15.392 & 14.264 & 13.850 \\
\hline Barreiras (BA) & 84.683 & 112.409 & 137.427 \\
\hline Catolândia (BA) & 3.040 & 2.396 & 2.612 \\
\hline $\begin{array}{l}\text { Formosa do Rio Preto } \\
\text { (BA) }\end{array}$ & 15.945 & 18.895 & 22.528 \\
\hline $\begin{array}{l}\text { Luís Eduardo } \\
\text { Magalhães (BA) }\end{array}$ & 6.600 & 18.757 & 60.105 \\
\hline $\begin{array}{l}\text { Riachão das Neves } \\
\text { (BA) }\end{array}$ & 20.016 & 21.439 & 21.937 \\
\hline $\begin{array}{l}\text { São Desidério (BA) } \\
\text { Fonte: Atlas do Desenvolvimento Humano 2013. }\end{array}$
\end{tabular}

Santos (2006) nos esclarece que essas cidades, as cidades do agronegócio, funcionam como pontos de interligação da agricultura moderna com o mundo e com as áreas mais dinâmicas do país. São também cidades comandadas "de fora", porque obedecem às lógicas do capital global que impõe suas ordens. Assim, essas regiões agrícolas modernizadas e cidades do agronegócio,

Atualmente funcionam sob um regime obediente a preocupações subordinadas a lógicas distantes, externas em relação à área da ação; mas essas lógicas são internas aos setores e às empresas globais que as mobilizam. Daí se criarem situações de alienação que escapam a regulações locais ou nacionais, embora arrastando comportamentos locais, regionais, nacionais em todos os domínios da vida, influenciando o comportamento da moeda, do crédito, do gasto público e do emprego, incidindo sobre o funcionamento da economia regional e urbana, por intermédio de suas relações determinantes sobre o comércio, a indústria, os transportes e os serviços. Paralelamente, alteram-se os comportamentos políticos e administrativos e o conteúdo da informação (SANTOS, 2006, p. 92-93).

As atividades agroindustriais se concentraram inicialmente em Barreiras, que por meio de uma rede moderna de atividades produtivas e de serviços, estruturada para servir às necessidades do agronegócio, 
consegue interligar-se com outros municípios também participantes da cadeia produtiva como Luís Eduardo Magalhães, São Desidério e Formosa do Rio Preto, atraindo também grande contingente populacional. Assim, para Dallacqua (2007, p.61) “Barreiras é conhecida como a capital da soja dos anos 80 e principal centro urbano dos Cerrados baianos".

Silva e Silva (2011) ao analisarem o crescimento populacional do estado da Bahia por microrregiões no período de 2000 a 2010 constataram que,

A Microrregião de Barreiras registra, o maior aumento populacional, com $38,67 \%$ de crescimento positivo, o que representa um ganho de 79.787 pessoas. É, por conseguinte, o melhor exemplo de crescimento demográfico no interior, por sinal, bem distante da metrópole, associado à dinâmica do agronegócio (Silva; Silva, 2011, p. 183).

Esse crescimento segundo as autoras supracitadas ocorreu tanto na zona rural quanto na urbana. Analisando o crescimento populacional na área rural as autoras afirmam que das 32 microrregiões baianas, apenas 6 tiveram aumento da população rural, incluindo a microrregião de Barreiras que aparece em primeiro lugar. Com relação ao crescimento da população urbana as autoras afirmam que "todas tiveram crescimento positivo. A Microrregião Geográfica de Barreiras foi a que muito mais cresceu do que as outras Microrregiões (47,88\%), mostrando o impacto do agronegócio também no meio urbano" (p. 194).

Dessa ação modernizadora que atrai a população, decorre um rápido processo de urbanização de Barreiras. Porém,

essa difusão do novo pela cidade de Barreiras é desigual e ambivalente, produtora de paradoxos através da pobreza também gerada em muitos bairros periféricos como, por exemplo, nos bairros Santa Luzia, Cascalheira, Santo Antônio, Conjunto Habitacional Rio Grande, Morada da Lua de Cima, Vila do Papelão, Vila Brasil (MONDARDO, 2010, p. 271).

A produção dessas periferias não se deve apenas aos migrantes descapitalizados que chegam à cidade como força de trabalho, ela é fruto também dos posseiros que perderam suas terras frente à implantação dos projetos da agricultura moderna e dos que foram impedidos de continuar utilizando as áreas de Cerrado para a pecuária extensiva.

O município de Luís Eduardo Magalhães, desmembrado de Barreiras em 2000 também apresentou grande crescimento populacional no período analisado com um incremento de aproximadamente 54 mil pessoas num período de duas décadas. Este município já desponta também como uma cidade do agronegócio agregando em seu território filiais de grandes multinacionais ligadas ao agronegócio. Apresenta também um grande crescimento do ICMS chegando a superar o de Barreiras no ano de 2010, despontando assim, como uma nova centralidade no Oeste Baiano.

Num outro extremo, ainda com base na tabela 1, encontramos municípios que perderam população, como é o caso de Baianópolis e Catolândia, municípios que ainda não foram incorporados completamente ao circuito produtivo do agronegócio e possuem economias menos dinâmicas.

Os municípios da microrregião de Barreiras que têm suas economias baseadas no agronegócio possuem grande arrecadação de impostos, porém, dados socioeconômicos mostram que a população desses municípios ainda não tem se beneficiado de forma mais ampla dos recursos gerados pela agricultura modernizada. A riqueza produzida pelo agronegócio concentra-se nas mãos de uma minoria detentora dos meios de reprodução do capital.

Com relação ao IDHM (Índice de Desenvolvimento Humano dos Municípios), percebe-se uma melhora no intervalo de tempo pesquisado, acompanhando a tendência nacional e estadual, porém, todos os municípios ainda possuem IDH inferiores ao do Brasil. Nesse quesito, destacam-se as cidades de Barreiras e Luís Eduardo Magalhães com os IDHs mais elevados, superando a média do estado da Bahia, conforme tabela 2 .

A análise do IDHM revela que ainda é preciso grandes investimentos em saúde e educação nos municípios da microrregião de Barreiras, bem como uma melhor distribuição de renda que ainda é muito concentrada, como veremos mais adiante.

A mortalidade infantil reduziu-se bastante em todos os municípios da microrregião no período analisado (tabela 3) acompanhando os avanços do país e do estado da Bahia, fruto de investimentos dos governos em saneamento básico, vacinas, acompanhamento pré-natal, dentre outros, porém, a maior parte dos municípios ainda encontra-se com índices de mortalidade infantil maiores que o do país, destacando-se apenas Luís Eduardo Ma- 
galhães que possui taxa inferior a do Brasil. Nesse sentido, a microrregião de Barreiras ainda carece de políticas mais efetivas no combate à mortalidade das crianças de menos de 1 ano, principalmente investimentos em saúde e saneamento básico que por sinal é de extrema precariedade nesses municípios. Ao andar pelas ruas de Barreiras e Luís Eduardo Magalhães, os municípios de maior pujança econômica da microrregião, não é difícil perceber que a população em geral ainda não é beneficiada com a modernização agrícola.

Tabela 2: IDHM da microrregião de Barreiras - BA, 1991 a 2010.

\begin{tabular}{l|r|r|r}
\hline Localidades & IDHM (1991) & IDHM (2000) & IDHM (201C \\
\hline Brasil & 0,493 & 0,612 & 0,7 \\
\hline Bahia & 0,386 & 0,512 & $0, \epsilon$ \\
\hline Baianópolis (BA) & 0,259 & 0,383 & 0,5 \\
\hline Barreiras (BA) & 0,408 & 0,572 & 0,7 \\
\hline Catolândia (BA) & 0,294 & 0,426 & 0,5 \\
\hline Formosa do Rio Preto (BA) & 0,376 & 0,449 & $0, \epsilon$ \\
\hline Luís Eduardo Magalhães & 0,391 & 0,547 & 0,7 \\
(BA) & 0,267 & 0,389 & 0,5 \\
\hline Riachão das Neves (BA) & 0,272 & 0,398 & 0,5 \\
\hline \multicolumn{2}{|r|}{ São Desidério (BA) } \\
Fonte: Atlas do Desenvolvimento Humano 2013.
\end{tabular}

Por fim, o índice de Gini e a desigualdade de renda mostram-nos uma microrregião com renda concentrada acompanhando a tendência histórica do Brasil (tabela 4). Embora a maioria dos municípios apresente índice de Gini melhor que o do país, a renda ainda se mostra concentrada, fruto de uma política de modernização da agricultura excludente, que não consegue incluir os pequenos produtores e ainda reforça a concentração fundiária que é um dos grandes males do Brasil, estimulando também o êxodo rural.

Tabela 3: Mortalidade infantil da microrregião de Barreiras - BA, 1991 a 2010.

\begin{tabular}{l|r|r|r}
\hline Localidades & $\begin{array}{l}\text { Mortalidade } \\
\text { infantil (1991) }\end{array}$ & $\begin{array}{l}\text { Mortalidade } \\
\text { infantil (2000) }\end{array}$ & $\begin{array}{l}\text { Mortalidade } \\
\text { infantil (2010) }\end{array}$ \\
\hline Brasil & 44,68 & 30,57 & 16,7 \\
\hline Bahia & 70,87 & 41,81 & 21,73 \\
\hline Baianópolis (BA) & 73,82 & 52,02 & 25 \\
\hline Barreiras (BA) & 65,79 & 34,71 & 18,1 \\
\hline Catolândia (BA) & 65,79 & 39,64 & 21,3 \\
\hline Formosa do Rio Preto (BA) & 65,79 & 44,73 & 25 \\
\hline Luís Eduardo Magalhães & 61,34 & 31,96 & 15,5 \\
(BA) & 75,3 & 46,26 & 22,4 \\
\hline Riachão das Neves (BA) & 65,84 & 44,73 & 28,9 \\
\hline São Desidério (BA) & & &
\end{tabular}

Fonte: Atlas do Desenvolvimento Humano 2013.

A implementação do agronegócio na microrregião de Barreiras mostra-se como um modelo de expansão do capitalismo baseado na concentração de renda, haja vista a riqueza produzida concentrar-se nas mãos de uma pequena parcela da população como pode ser observado na tabela 5 .

Tabela 4: Índice de Gini da microrregião de Barreiras - BA, 1991 a 2010

\begin{tabular}{|c|c|c|c|}
\hline Localidades & $\begin{array}{l}\text { Índice de Gini } \\
(1991)\end{array}$ & $\begin{array}{l}\text { Índice de Gini } \\
(2000)\end{array}$ & $\begin{array}{l}\text { Índice de Gini } \\
(2010)\end{array}$ \\
\hline Brasil & 0,63 & 0,64 & 0,60 \\
\hline Bahia & 0,67 & 0,66 & 0,62 \\
\hline Baianópolis (BA) & 0,54 & 0,70 & 0,57 \\
\hline Barreiras (BA) & 0,60 & 0,62 & 0,56 \\
\hline Catolândia (BA) & 0,53 & 0,53 & 0,51 \\
\hline Formosa do Rio Preto (BA) & 0,74 & 0,80 & 0,60 \\
\hline $\begin{array}{l}\text { Luís Eduardo Magalhães } \\
\text { (BA) }\end{array}$ & 0,71 & 0,63 & 0,62 \\
\hline Riachão das Neves (BA) & 0,51 & 0,57 & 0,53 \\
\hline São Desidério (BA) & 0,59 & 0,55 & 0,57 \\
\hline
\end{tabular}

Tabela 5: Desigualdade de renda da microrregião de Barreiras - BA, 2010

\begin{tabular}{l|r|r}
\hline & $\begin{array}{l}\text { Percentual da renda } \\
\text { apropriada pelos } \\
\text { 20\% mais pobres } \\
\text { Localidades }\end{array}$ & $\begin{array}{l}\text { Percentual da renda } \\
\text { apropriada pelos } \\
\text { 20\% mais ricos } \\
(2010)\end{array}$ \\
\hline Brasil & 2,41 & 63,40 \\
\hline Bahia & 1,98 & 65,06 \\
\hline Baianópolis (BA) & 1,46 & 58,92 \\
\hline Barreiras (BA) & 3,22 & 60,79 \\
\hline Catolândia (BA) & 1,74 & 52,94 \\
\hline Formosa do Rio Preto (BA) & 1,02 & 61,28 \\
\hline Luís Eduardo Magalhães (BA) & 2,99 & 65,52 \\
\hline Riachão das Neves (BA) & 1,31 & 54,27 \\
\hline São Desidério (BA) & 1,03 & 58,58 \\
\hline
\end{tabular}

Dessa forma, percebemos que a introdução do agronegócio na microrregião não foi capaz de reduzir a concentração de renda, embora tenha havido uma ligeira redução da concentração entre 1991 e 2010, os índices provam que é urgente uma melhor distribuição da renda produzida nesse espaço. Isso fica mais visível quando percebemos o percentual da renda apropriada pelos $20 \%$ mais pobres e os $20 \%$ mais ricos, a discrepância é nítida, carecendo de correção urgente para um maior desenvolvimento social da microrregião de Barreiras.

\section{CONSIDERAÇÕES FINAIS}

O processo de apropriação do Cerrado baiano pelo agronegócio se concretiza enquanto uma expansão da modernização da agricultura brasileira, uma estratégia de ampliação do capitalismo em sua fase atual, o capitalismo global. Dessa forma, em busca de novos territórios para a ampliação 
dos meios de produção, o capitalismo através de sujeitos individuais capitalizados, principalmente os sulistas, empresas e o Estado, empreende a ação modernizadora dos cerrados baianos, submetendo o território a novos usos, a partir da inserção de ciência, da técnica e da informação. Esses investidores sentem-se atraídos principalmente pelo baixo custo das terras, e têm no Estado um ponto de apoio a partir de projetos modernizadores e financiamentos através de bancos públicos bem como o investimento em infraestrutura que possibilitou a integração dessa porção do espaço baiano com outros espaços estratégicos, condicionando assim, a fluidez do território.

Dessa forma, o Oeste da Bahia que permaneceu até a primeira metade do século XX como um imenso território de reserva, com baixa ocupação populacional e economia baseada na agropecuária de subsistência praticada nos moldes tradicionais, passa, a partir do final da década de 1970, a receber investimentos a partir de uma agricultura moderna para a produção de grãos (inicialmente a soja, depois milho) e algodão na forma de commodities para atender principalmente o mercado internacional. Nesse sentido,

A geografia de espaços reduzidos e tempos de longa duração dos antigos habitantes dos sertões vê-se, radicalmente alterada por esse novo cenário dos complexos agroindustriais que impõe o tempo breve, veloz da técnica e do lucro arrasador e a escala macro das grandes explorações capitalistas (HAESBAERT, 1996, p. 378).

Nesse cenário, despontam as cidades de Barreiras inicialmente, e mais recentemente, Luís Eduardo Magalhães, enquanto cidades do agronegócio, servindo como pontos de interligação d a agricultura moderna/científica produzida na região com o os centros mais dinâmicos do país e o mundo.

A entrada do agronegócio na microrregião de Barreiras acarretou um grande fluxo migratório e consequentemente um crescimento populacional na maioria dos municípios desta porção do espaço baiano principalmente nas cidades diretamente relacionadas com a agricultura moderna. Porém, a análise de alguns dados socioeconômicos, baseados nos censos demográficos de 1991, 2000 e 2010, mostra-nos que na microrregião de Barreiras - BA ainda há a necessidade de muitos investimentos em saúde e educação, bem como uma melhor distribuição de renda. Alem disso, o grande fluxo migratório de trabalhadores para a região e o êxodo rural de muitos posseiros que perderam suas terras, possibilitou a criação de muitas periferias principalmente em Barreiras.

\section{REFERÊNCIAS BIBLIOGRÁFICAS}

ATLAS DE DESENVOLVIMENTO HUMANO 2013. Disponível em: http:/ / atlasbrasil.org.br/2013/pt/o_ atlas/o_atlas_/. Acesso em: 10-20 dez. 2015.

BRANDÃO, P. R. B. Um território indiferenciado dos sertões: a geografia pretérita do Oeste Baiano (1501-1827). Boletim Goiano de Geografia. Goiânia-GO, v. 29, nº 1 , p. 47-56, jan/jun 2009.

BRANDÃO, P. R. B. A formação territorial do Oeste Baiano: a constituição do "Além São Francisco" (1827-1985). Geo Textos, Salvador-BA, v. 6, no 1, p. 35-50, jul 2010.

CALAÇA, M. Abordagem sobre a territorialização do capital no cerrado. In: Encontro Nacional da ANPEGE, n. 09. Goiânia-GO. Anais. 2011.

DALL'ACQUA, C. T. B. Planejamento Territorial do Desenvolvimento: ação técnica e ação política - uma prática piloto na região de Barreiras. Tese (Doutorado em Geografia), São Paulo: USP, 2007, 183 p.

DINIZ, J. A. F. A área centro-ocidental do Nordeste. Recife: Superintendência do Desenvolvimento do Nordeste, 1982.

GOMÉZ, G. M. Razón y pasión del espacio y el territorio. In:__ et. al. (Orgs.) Espacio y territorios: razón, pasión y imaginarios. Bogotá: Unobiblos, 2001. p. 15-32.

HAESBAERT, R. "Gaúchos" e baianos no "novo" Nordeste: entre a globalização econômica e a reinvenção das identidades territoriais. In: CASTRO, I. E. de. GOMES, P. C. da C. CORRÊA, R. L. (Orgs.). Brasil: questões atuais da reorganização do território. Rio de Janeiro, Bertrand Brasil, 1996, p. 367-418. 
MATOS, P. F.; PESSÔA, V. L. S. A apropriação do Cerrado pelo agronegócio e os novos usos do território. Campo-território: revista de geografia agrária, v. 9, n. 17, p. 6-26, abr. 2014.

MENDONÇA, M. R. A urdidura do capital e do trabalho nas áreas de Cerrado. In: THOMAZ JUNIOR, A.; OLIVEIRA, A. M. S. de; GONÇALVES, M, A. (Org.). Geografia e trabalho no século XXI. Presidente Prudente: Centelha/ CEGeT, 2007. p. 84-106. 2006, v.3.

MONDARDO, M. L. Da migração sulista ao novo arranjo territorial no Oeste baiano: "territorialização" do capital no campo e paradoxos na configuração da cidade do agronegócio. Campo-território: revista de geografia agrária, v. 5, n. 10, p. 259-287, ago. 2010.

RAFFESTIN, C. Por uma Geografia do poder. São Paulo: Ática, 1993.

SANTOS, M. O dinheiro e o território. In: et. al. (Orgs.). Território, territórios: ensaios sobre o ordenamento territorial. Rio de Janeiro: Lamparina, 2002. p. 0915.

SANTOS, M. A natureza do espaço: técnica e tempo, razão e emoção. 4. ed. São Paulo: EDUSP, 2004.

SANTOS, M. Por uma outra globalização: do pensamento único à consciência universal. $13^{\mathrm{a}} \mathrm{ed}$. Rio de Janeiro: Record, 2006. 174 p.

SILVA, B.C. N.; SILVA, M. P. Crescimento Demográfico no Estado da Bahia, 2000 A 2010: uma contribuição estatístico-cartográfica. GeoTextos, vol. 7, n. 2, p. 179-208, dez. 2011.

THURIOT, F. Cultures et territories: Les voies de la cooperation. Paris: Editions L'Harmattan, 1999.

\section{Notas de Fim:}

1- Os dados de 1991 referem-se ao então povoado de Mimoso do Oeste, pertencente ao município de Barreiras. Este povoado desmembrou-se de Barreiras em 2000 tornando-se o município de Luís Eduardo Magalhães.

\section{Correspondência da autora:}

Rita de cássia evangelista dos santos e-mail: cassiacollins@yahoo.com.br

Artigo recebido em: 18/03/2016

Revisado pelos autores em: 04/06/2016

Aceito para publicação em: 13/06/2016 